\title{
Evolution of Market Uncertainty around Earnings Announcements
}

\author{
Dušan Isakov* \\ Christophe Pérignon ${ }^{\S}$
}

Version: June 2000

We are grateful to Tony Berrada, Guido Bolliger, Michel Dubois, Rajna Gibson-Asner, Henri Loubergé, Nicolas Mougeot, René Stulz, an anonymous referee, seminar participants at the French Finance Association meeting in Lille, the Midwest Finance Association meeting in Chicago, the Swiss Society for Financial Market Research in Zurich, the ESSEC Business School, the University of Grenoble, the University of Lausanne, the University of Rennes for helpful comments. We gratefully acknowledge the contribution of I/B/E/S International Inc. for providing earnings per share forecast data and thank Rajna Gibson-Asner and François-Serge Lhabitant for providing the data on options quoted on the SOFFEX. All remaining errors are ours.

* HEC-University of Geneva and FAME; 40, Boulevard du Pont-d'Arve; CH-1211 Geneva 4; Switzerland. Phone: +41 22 - 70586 11; Fax: +41 22 - 70581 04; Email: dusan.isakov@ hec.unige.ch.

$\S$ Department of Economics-University of Geneva and FAME; 40, Boulevard du Pont-d'Arve; CH-1211 Geneva 4; Switzerland. Phone: +41 22 - 70582 69; Fax: +41 22 - 70582 93; Email: perignon@ ecopo.unige.ch. 


\title{
Evolution of Market Uncertainty around Earnings Announcements
}

\begin{abstract}
This paper investigates theoretically and empirically the dynamics of the implied volatility (or implied standard deviation - ISD) around earnings announcements dates. The volatility implied by option prices can be interpreted as the level of volatility expected by the market over the remaining life of the option. We propose a theoretical framework for the evolution of the ISD that takes into account two well-known features of the instantaneous volatility: volatility clustering and the leverage effect. In this context, the ISD should decrease after an earnings announcement but the post-announcement ISD path depends on the content of the earnings announcement: good news or bad news. An empirical investigation is conducted on the Swiss market over the period 1989-1998.
\end{abstract}




\section{Executive summary}

Alternative statistical methods are available to estimate the volatility of stock returns. The majority of them reflects the past evolution of the market as they are based on historical data. The only forward-looking measure of market uncertainty can be obtained from derivative markets by computing the implied standard deviation (ISD) from option prices. Technically, the ISD is the volatility parameter which makes the option price obtained from a theoretical option pricing model equal to the option price observed on the market. This paper focuses on the behaviour of the implied volatility around earnings announcements and provides new results about the way market participants' perceptions of future volatility change around this event.

The theoretical model of the evolution of uncertainty builds on the work of Merton (1973), who states that the implied volatility represents the average instantaneous volatility until the expiration of the option if the instantaneous volatility is a deterministic function of time. This property is particularly interesting as it means that the behaviour of the implied volatility around earnings announcement dates depends on the expectations of market participants concerning the evolution of the instantaneous volatility until the expiration of the option. The standard model of the evolution of ISD assumes that the instantaneous volatility is constant except on the disclosure date, where it rises because of the uncertainty linked to the content of the announcement. This assumption implies that the pattern that should be observed in terms of implied volatilities is a rise before the announcement date, a peak on the day before the announcement and a fall to its long-term level on the disclosure date. We modify the framework by taking into account two well-known features of the instantaneous volatility: volatility clustering and the leverage effect. Volatility clustering can be defined as the presence of autocorrelation in volatility. It means that a day of high (or low) volatility is very likely to be followed by a day of high (or low) volatility. The leverage effect was first expounded by Black (1976) and relates to the way the instantaneous volatility reacts to past news. To be more precise, the volatility has been shown to increase more after a negative shock (bad news) than after a positive shock (good news). These two features imply that the evolution of ISD around earnings announcements should be slightly different. The evolution of ISD before the disclosure date is unchanged but, after the announcement, the patern may be different. The ISD should not drop sharply to its long-term level on the announcement day. Moreover after a bad news the ISD should be higher than after a good news. 
The evolution of the ISD is also investigated empirically over the period January 1989-May 1998 using daily data from the Swiss stock and option markets. We computed the ISD 10 days before and after earnings announcement dates for 17 firms. The final sample contains 178 announcement of annual and semi-annual results. The empirical results indicate that on average it takes 4 days to the ISD to reach its long term level which is in favour of the volatility clustering hypothesis. The leverage effect is also investigated by dividing the sample in two different subsamples: the good news and the bad news. Two partition criteria are used to determine the subsamples. The first one is the abnormal return on the announcement date, i.e. the return of the stock minus the return on the market. The second is the earnings surprise, i.e. the difference between the realized earnings and the earnings that have been forecasted by financial analysts. For both measures we use a $0 \%$ breakpoint to discriminate between good and bad news. The empirical results indicate that, after a negative abnormal returns, the ISD is slightly higher than after a good news. This result is in favour of the leverage effect assumption. When using earnings surprises we find no difference in the evolution of the ISD. This means that this partition criteria does not capture the same type of information as abnormal returns. As the variation of ISD are relatively small (about 1\%), we suspect that any trading strategy based on these results would not be profitable. 


\section{Evolution of Market Uncertainty around Earnings Announcements}

\section{Introduction}

The impact of information disclosures on asset returns is the focus of many studies in financial economics. Since the seminal work of Ball and Brown (1968) attention has concentrated on the effect of information releases on stock returns. This literature finds generally that stock prices adjust relatively quickly to the information contained in earnings announcements, which confirms the efficient market hypothesis. An issue which has received far less attention in previous research is the impact of firm-specific news on the uncertainty regarding the evolution of future stock prices. Different methods are available to estimate the volatility of stock prices but most of them reflect the past as they are based on historical data. The only forward-looking measure of market uncertainty can be obtained from derivative markets by computing the implied standard deviation from option prices. Our paper focuses on the behaviour of the implied volatility around earnings announcements and provides new results about the way market participants' perceptions of future volatility change around this event.

Patell and Wolfson (1979) were the first to investigate this issue both theoretically and empirically on the US market. Their theoretical model of the evolution of uncertainty builds on the work of Merton (1973), who states that the implied volatility represents the average instantaneous volatility until the expiration of the option if the instantaneous volatility is a deterministic function of time. This property is particularly interesting as it means that the behaviour of the implied volatility around earnings announcement dates depends on the expectations of market participants concerning the evolution of the instantaneous volatility until the expiration of the option. Patell and Wolfson (1979) assume that the instantaneous volatility is constant except on the disclosure date, where it rises because of the uncertainty linked to the content of the announcement. If this is true, the pattern that should be observed in terms of implied volatilities is a rise before the announcement date, a peak on the day before the announcement and a fall to its long-term level on the disclosure date. They investigate empirically the evolution of the implied standard deviation (ISD) around annual earnings announcement dates on a sample of 83 events (28 firms quoted on the Chicago Board Options Exchange over the period 1974-1978). The ISD are computed from call 
options prices by inverting the Black-Scholes formula. The results display a pattern which is relatively similar to what they assumed, except that it takes several days for the ISD to fall to its long-term level. Patell and Wolfson (1981) repeat the empirical investigation on a similar period but on a larger sample which also includes interim earnings announcements. Consistent with their assumptions, they report a significant increase in the ISD on the 20 days before the announcement date and a significant drop two days after. Donders and Vorst (1996) investigate the same issue on the Dutch market. They use a sample of 96 interim and annual earnings announcements of 23 firms over the period 1991-1992. Their results are more pronounced than those obtained for the US market in the sense that the implied volatility increases significantly during the pre-event period and reaches a maximum on the day preceding the announcement date. On the event date, they report a sharp decrease in the implied volatility and a strong increase in the instantaneous volatility, which is consistent with Patell and Wolfson's assumptions on the evolution of the ISD. Their results are qualitatively similar when they are adjusted for the market implied volatility extracted from stock index options. Finally, the authors simulate a trading rule based on the observed features of the ISD. Although the implied volatilities vary widely, the investment strategies based on predictable changes in the ISD are not economically significant once transaction costs are taken into account. Donders, Kouwenberg and Vorst (2000) broaden the scope of the previous study by considering more events on the Dutch market (190 earnings announcements over the period 1991-1993), computing the ISD from call and put options and analysing such microstructure features of the options market as volume, open interest and spread. The conclusions are similar to those obtained in Donders and Vorst (1996) except that it takes the ISD two days to decrease to normal levels. Using Finnish data, Sahlström (2000) reports a high level of implied volatility prior to earnings announcements and a significant decline after the event.

The impact on the ISD of unscheduled firm-specific news has also been studied in the literature. French and Dubofsky (1986) and Sheikh (1989) investigate the effect of stock split announcements on the ISD. They report first that, the ISD does not anticipate stock splits and second, that the ISD is higher after the announcement. Levy and Yoder (1993) consider the case of mergers and acquisitions in the US: they report that the ISD of the target firms increases on the announcement date and does not drop as in the case of scheduled announcements. Periodic macroeconomic information released by government agencies and central banks significantly affects investors' expectations about uncertainty. Bailey (1988) documents the statistical associations between money surprises and ISD inferred from prices 
of derivatives on the stock index, Treasury bonds, exchange rates and gold prices. Using options on interest rates and exchange rates futures, Ederington and Lee (1996) confirm that scheduled macroeconomic releases generally lead to a drop in the ISD as the uncertainty regarding the impact of the announcement on the security price is resolved. Conversely, most major unscheduled announcements cause an increase in market uncertainty and a rise in the ISD.

Our paper enriches the literature on the evolution of the ISD around earnings announcement dates. It provides an alternative framework for analysing the behaviour of the ISD that takes into account two well-known empirical features of the instantaneous volatility, namely volatility clustering and the leverage effect. Volatility clustering can be defined as the presence of autocorrelation in volatility. It means that a day of high (or low) volatility is very likely to be followed by a day of high (or low) volatility. The leverage effect was first expounded by Black (1976) and relates to the way the instantaneous volatility reacts to past news. To be more precise, the volatility has been shown to increase more after a negative shock (bad news) than after a positive shock (good news). This type of distinction regarding the informational content of the disclosure is common in the classical literature on the reaction of stock returns to earnings announcements but has been explored only by Donders, Kouwenberg and Vorst (2000) in the case of the ISD. This paper provides a theoretical framework for the dynamics of the ISD. It also documents it empirically over the period January 1989-May 1998 using daily data from markets where these issues have not been investigated so far: the Swiss stock and option markets.

The rest of the paper is organised as follows. The next section presents our propositions about the evolution of the ISD around earnings announcements and associated testable implications. Section 3 presents the data, the methodology for computing the ISD and the criteria used to discriminate between good and bad news. Section 4 provides the results of the empirical analysis performed on the Swiss market, while section 5 summarises the paper and offers some concluding remarks. 


\section{Evolution of the ISD around earnings announcements}

\subsection{The theoretical framework}

In order to predict the evolution of the ISD around earnings announcements, it is necessary to give an economic interpretation of the implied volatility. Technically, the ISD is the volatility parameter which makes the option price obtained from a theoretical option pricing model equal to the option price observed on the market. More specifically, Merton (1973) states that an instantaneous volatility that varies deterministically through time is consistent with the classical Black and Scholes (1973) option pricing formula, which assumes constant volatility. $\mathrm{He}$ asserts that in this case today's implied volatility, $I S D_{0}$, represents the average of the instantaneous volatility, $\sigma^{2}(t)$, until $\tau$, the maturity of the option. ${ }^{1}$

$$
I S D_{0}=\sqrt{\frac{1}{\tau} \int_{0}^{\tau} \sigma^{2}(t) d t}
$$

Heynen, Kemna and Vorst (1994) show that a similar interpretation holds, under simplifying assumptions, when the instantaneous volatility moves stochastically through time, as in the model of Hull and White (1987), and also when the instantaneous volatility follows a GARCH process, as in the model of Duan (1995). The implied volatility is therefore a forward-looking measure of uncertainty. It provides the market's assessment of the average volatility that will affect stock prices until the expiration of the option.

We first review the standard model of evolution of the ISD that is described in the literature. ${ }^{2}$ In the case of scheduled information, investors know that some information will be released on a precise date, prior to the maturity of the option, and expect a higher instantaneous volatility on that day as there is uncertainty with respect to the informational content of the announcement. Assuming that no other event happens in this time period, one would expect that the implied volatility should significantly decrease after some scheduled information disclosures. This should be accompanied by a higher instantaneous volatility (positive or negative price change) on the event date. This idea can be rewritten in a more formal way by

\footnotetext{
${ }^{1}$ Several papers test this relation empirically. In particular, they investigate whether the implied volatility is a good predictor of future realised volatility or not. See for instance Christensen and Prabhala (1998), Adjaoute, Bruand and Gibson-Asner (1998) and the references therein.
} 
defining $\sigma_{\text {normal }}^{2}$ as the level of volatility on a day when there is no news announcement and $\sigma_{\text {high }}^{2}$ as the level of volatility on a day when scheduled information is released. The implied standard deviation $\left(\mathrm{ISD}_{0, \tau}\right)$ on day 0 is the average volatility until the maturity of the option $\tau$.

$$
I S D_{0, \tau}=\sqrt{\frac{\tau-1}{\tau} \sigma_{\text {normal }}^{2}+\frac{1}{\tau} \sigma_{\text {high }}^{2}}
$$

where $\tau$ is the number of days until the expiration of the option. Figure 1 depicts the evolution of uncertainty according to this set of assumptions. The bars represent the instantaneous volatility (IV), which is constant except on the announcement date, and the line depicts the evolution of the implied volatility (ISD). According to this model, the ISD should increase gradually and reach a peak on the day before the announcement, as investors expect the instantaneous volatility to be higher on the earnings disclosure date. It should then drop to its long-term level on the announcement date, as the uncertainty linked to the content of the announcement is resolved and assuming that no more instantaneous volatility shocks are to be expected until the maturity of the option.

\section{Figure 1: Standard model of evolution of ISD and IV around earnings announcements}

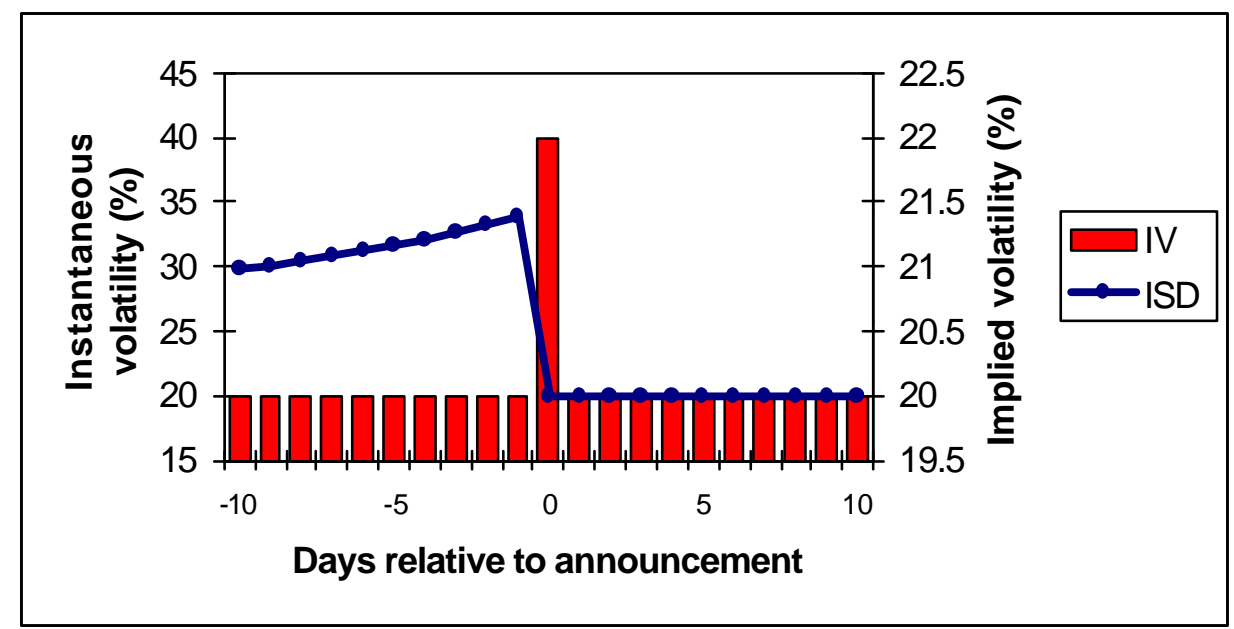

Note: IV is the instantaneous volatility and ISD the implied standard deviation. This figure is obtained assuming the following values of the parameters: the maturity of the option is 20 days after the event date, IV $=20 \%$ except on the announcement date when it is equal to $40 \%$. The ISD is obtained with the model described in equation (2).

\footnotetext{
${ }^{2}$ This is the model used in Patell and Wolfson (1979, 1981), Donders and Vorst (1996) and Donders,
} 
For almost two decades, the empirical literature on the dynamic behaviour of volatility has recognised a certain number of stylised facts. One of these recurrent observations is that there is a certain persistence in volatility shocks. In other words, when volatility rises abruptly it then takes some time to return to normal. ${ }^{3}$ In our context, it seems reasonable to assume that higher volatility persists after a disclosure of information. It may take some time for the market participants to interpret the content of the earnings announcement and reach a consensus about the future prospects of the firm on the basis of this new piece of information. This means that the instantaneous volatility may be at slightly higher than normal for some days. If investors expect this phenomenon to happen after an earnings announcement, it will be reflected in the evolution of the ISD. Using the same type of graph as in figure 1 and according to the dynamics described by equation (1), we show in figure 2 how the ISD should be affected by this feature of the IV.

\section{Figure 2: Evolution of ISD and IV assuming persistence in volatility}

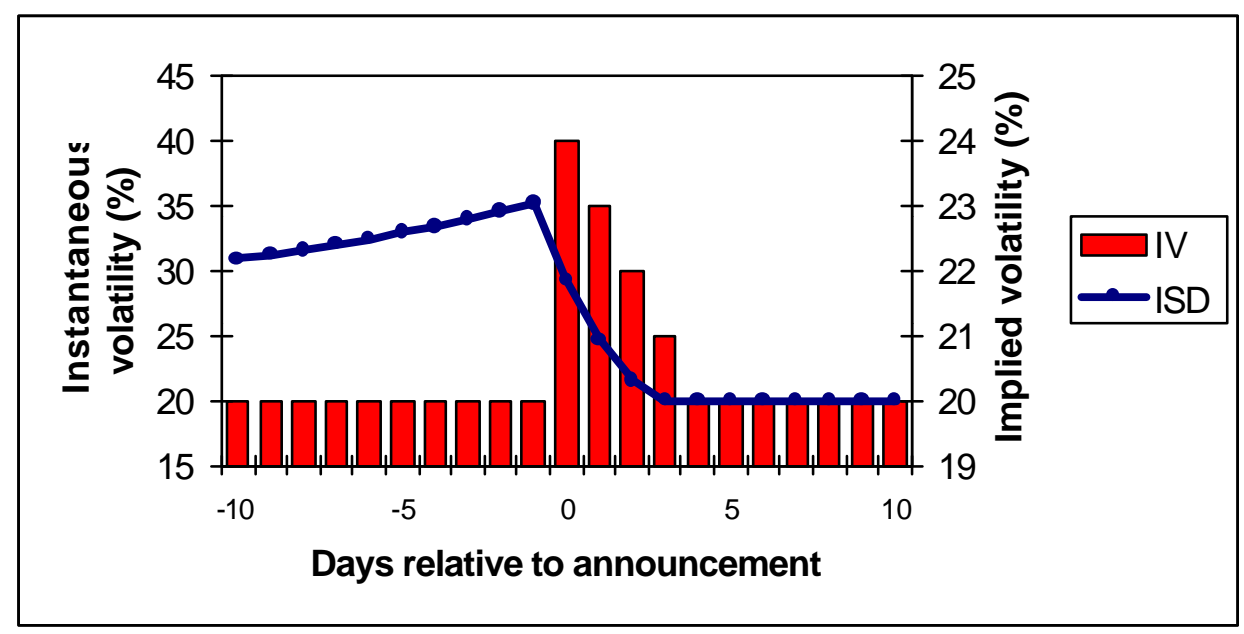

Note: IV is the instantaneous volatility and ISD the implied standard deviation. This figure is obtained assuming the following values of the parameters: the maturity of the option is 20 days after the event date, $\mathrm{IV}_{\mathrm{t}}=20 \%$ except $\mathrm{IV}_{0}=40 \%, \mathrm{IV}_{1}=35 \%, \mathrm{IV}_{2}=30 \% \mathrm{IV}_{3}=25 \%$. The ISD is obtained with a discrete version of the model described in equation (1).

The first difference with the classical case is that the ISD is higher before the announcement date as investors expect that there will be increased instantaneous volatility for some days after the event. The second difference is that the ISD decreases progressively to its long-term

Kouwenberg and Vorst (2000).

${ }^{3}$ See for instance the literature on GARCH models which is surveyed in Bollerslev, Chou and Kroner (1992). 
level. The number of days it takes to reach its long-term level depends on the degree of persistence of a volatility shock. In figure 2, we assume that it takes 3 days. This volatility clustering may explain why the previous literature finds that in several cases the ISD decreases to its long-term level gradually and not on the announcement date, as assumed in the classical framework.

A second well-known feature of the empirical literature on the dynamics of volatility is the so-called leverage effect already identified by Black (1976). This effect implies that a negative shock (bad news) has a larger impact on volatility than a positive shock (good news) of the same magnitude. In our specific case, this means that if there is bad news (typically that the earnings of the company have been disappointing compared to the market's expectations) the instantaneous volatility may not decrease as much as in the case of a good news. This will also change the behaviour of the ISD around the announcement date but in a different fashion than that proposed in figure 2. As the content of earnings announcements is unknown, it cannot be accounted for before the disclosure date. We show in figure 3 that, according to the leverage effect, the instantaneous volatility should be greater after bad news than after good news. Therefore, the post-announcement ISD should be larger after bad news than after good news.

IV GOOD represents the evolution of the instantaneous volatility assuming persistence, as in figure 2. IV BAD is the additional instantaneous volatility induced by the revelation of the unexpected bad news on day 0 . As before, we assume that the additional volatility does not disappear immediately. This seems reasonable, as the market has to adjust to this unexpected information and has to analyse the new prospects of the firm. The effect on the ISD is unchanged up to the day before the announcement when the market is not expecting this bad news. On day 0 , the market discovers the informational content of the announcement and expects a higher instantaneous volatility due to the bad news on the days following the event. This is why the ISD path after a bad news release is higher than the ISD after a good news release. 
Figure 3: Evolution of ISD and IV assuming persistence in volatility and leverage effect

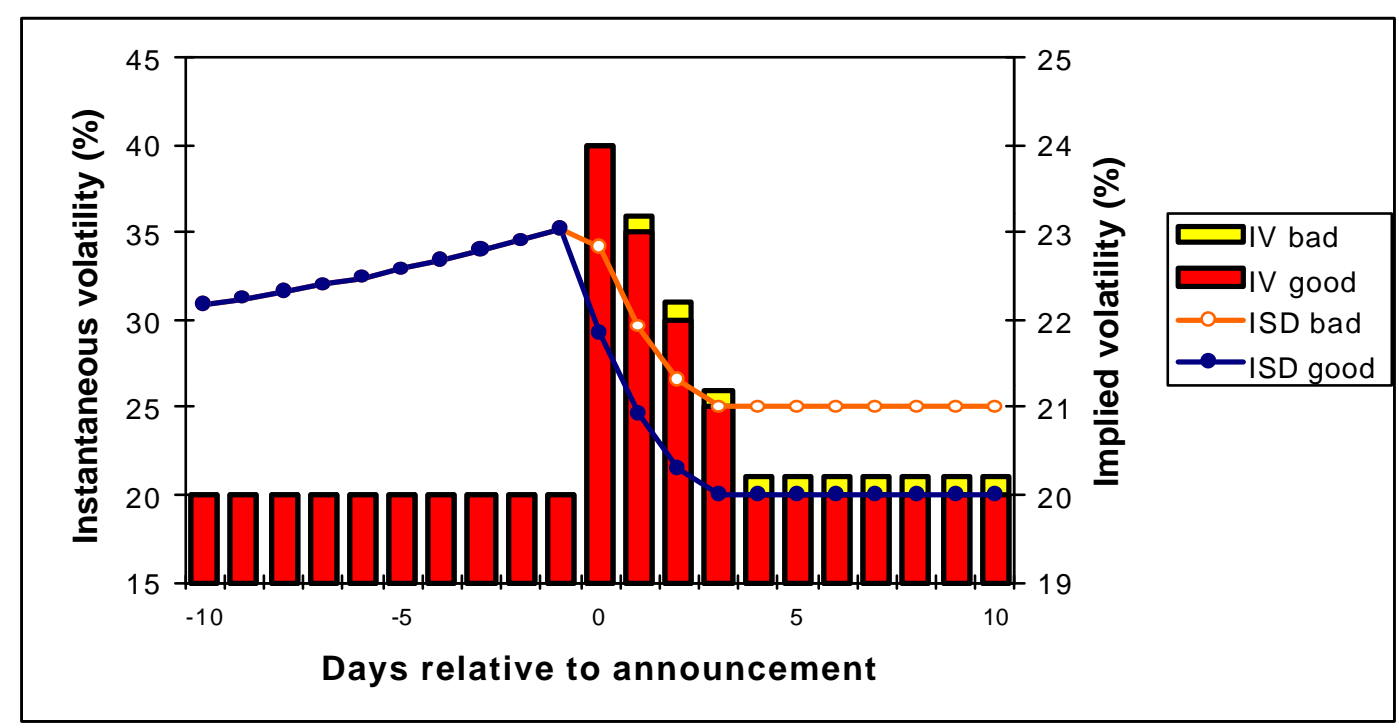

Note: IV is the instantaneous volatility, IV BAD is the instantaneous volatility induced by the revelation of bad news on the announcement date and ISD is the implied standard deviation. This figure is obtained assuming the following values of the parameters: the maturity of the option is 20 days after the event date, the $\mathrm{IV}_{\mathrm{t}}=20 \%$ except $\mathrm{IV}_{0}=40 \%, \mathrm{IV}_{1}=35 \%, \mathrm{IV}_{2}=30 \% \mathrm{IV}_{3}=25 \%$. In the case of a bad news announcement, the instantaneous volatility between 1 and 20 is increased by $1 \%$. The ISD is obtained with a discrete version of the model described in equation (1).

\subsection{Testable implications}

The theoretical framework proposed above provides several testable implications. A feature common to all models of ISD behaviour around earnings announcement dates is that the ISD should rise until the eve of the earnings announcement. This is due to the fact that the market anticipates a volatility shock on the event date whatever the informational content of the earnings announcement. This defines the first testable implication:

\section{I1: The ISD increases before earnings announcement dates.}

A second implication common to all the models is that the ISD returns to its long-term level after the information disclosure. In the case of bad news, this may not be true in the very short term but after a few days it should also go back to its long-term level once the market has adjusted to the new information. This defines the second testable implication:

I2: The ISD decreases after the earnings announcement date. 
The third implication is related to the difference between good and bad news. In the case of good news, the model assumes that the ISD should fall on the announcement date as a large part of the uncertainty linked to the announcement is removed. This may not be the case after a bad news announcement because there are two effects working in opposite directions: first, the revelation of information makes the ISD fall and second, the leverage effect increases the ISD in the post-event period.

I3: For good news announcements, the ISD falls on the earnings announcement date.

One way of discriminating between the classical model of ISD evolution around earnings announcements and our model assuming volatility clustering is to observe the behaviour of the ISD over a few days after the announcement date. If it drops on the event date and remains stable thereafter, this will favour the Patell and Wolfson assumption. On the other hand, if it continues to decline on the few days after the announcement date, this will be evidence in favour of the model assuming the persistence of volatility shocks, as in figure 2 . The fourth testable implication is linked to information disclosures containing bad news. According to the leverage effect, the post-bad news announcement ISD path should lie above the post-good news announcement ISD path. We therefore have the following implication:

I4: The ISD is higher during a post-bad news announcement period than during a post-good news announcement period.

Whether these implications are borne out by the markets is an empirical question. Volatility clustering seems to be present according to some previous results in the literature but the differential effect of good and bad news on the ISD has never been considered before. The rest of the paper is devoted to an empirical investigation of these issues on the Swiss market, a market that has not been considered in the previous literature. 


\section{The data}

\subsection{Stock prices and earnings announcement dates}

The evolution of the ISD around Swiss firms' earnings announcements is investigated using daily data over the period January 1989-May 1998. Our sample can be considered as representative of the Swiss market as it contains data on all the companies that have quoted options on the Swiss Options and Financial Futures Exchange (SOFFEX, now EUREX) and covers the market almost since its inception in 1988. Analysing earnings announcements over a longer period than previous studies offers an important advantage in that it covers various economic conditions, which increases the probability of having all types of business conditions and therefore having earnings announcements with positive and negative content. Our sample contains data on 17 firms, namely, ABB-BBC, Alusuisse, Ciba-Geigy, Ciba SC, Clariant, Crédit Suisse, Holderbank, Nestlé, Novartis, Roche, Sandoz, Swiss Ré, SBS, SMH, UBS, Winterthur and Zurich. Daily closing prices for stocks and the date and amount of dividends are retrieved from Datastream International. This is also the source of the interest rate for the 1-month Euroswiss Franc contracts which is used to represent the risk-free rate.

Contrary to the United States but like most European countries, Switzerland has no publication or service which systematically records earnings announcement dates and their content. We obtained these dates by direct correspondence with the companies and we systematically checked them using the Swiss financial newspaper Neue Zürcher Zeitung and to some extent the Reuters Business Briefing database. Our final sample contains 178 events. During the period under analysis, the companies studied announced earnings once or twice per year. As Swiss firms disclose earnings very regularly, it is reasonable to assume that these events are fully anticipated by market participants. This is corroborated by the fact that different financial newspapers announce the date of the earnings announcements and that some investment services predict their content.

\subsection{Option prices and computation of the ISD}

The first attempt to evaluate a stock's future volatility by means of the ISD was made by Latané and Rendleman (1976). They match the observed option prices with those computed 
with the Black and Scholes (1973) formula to get the ISD. In our case, this formula appears inappropriate because the model assumes that the options are of the European type and that they do not pay dividends. The options on individual stocks on the Swiss market are in fact American-type options on dividend-paying stocks and can therefore be exercised prematurely. In order to take into account the early exercise premium of American options, the Roll-GeskeWhaley formula is the most appropriate. ${ }^{4}$ This formula gives the value of an American call option on a stock paying a single dividend until the expiration of the option. Moreover, when there is no dividend during the remaining life of the option, this formula is equivalent to the Black and Scholes formula. Using the current call option price, underlying stock price, riskfree interest rate, exercise price and time to maturity of the option, the ISD is computed using a Newton-Raphson iterative search procedure. To overcome the problems related to the nonuniqueness of input data (various times-to-maturity and various exercise prices) of the stock ISD, most of the authors in this literature justify their choices by empirical evidence and seldom by theoretical arguments. In the empirical part of this paper, we compute the ISD on at-the-money call options close to maturity but with at least 20 days to maturity. The choice of using at-the-money options is mainly motivated by the fact that they are the most liquid and therefore avoid problems linked to liquidity and the non-synchronicity of stock and option prices. ${ }^{5}$ The choice of a minimal maturity of 20 days is motivated by the fact that the ISD computed with options very close to maturity presents some unusual behaviour. ${ }^{6}$

\subsection{Determination of good and bad news}

In order to analyse the effect on the ISD of earnings disclosures with different informational contents, the total sample is divided into two subsamples, the good news and the bad news, according to two partition criteria. The first is the difference between actual earnings per share (EPS) and the consensus (median EPS) forecast by financial analysts surveyed by the Institutional Brokers Estimate System $(\mathrm{I} / \mathrm{B} / \mathrm{E} / \mathrm{S})$. The financial analysts' forecast error is obtained as follows: $\varepsilon=\left(\mathrm{EPS}_{\mathrm{t}}-\mathrm{FY} \mathrm{Y}_{\mathrm{t}}\right) /\left|\mathrm{EPS}_{\mathrm{t}}\right|$, where $\mathrm{EPS}_{\mathrm{t}}$ represents the observed earnings per share on date $\mathrm{t}$ and $\mathrm{FY}_{\mathrm{t}}$ the median forecast earnings per share with a one-year horizon. This criterion is a classic unexpected earnings measure which seems to be a powerful indicator of

\footnotetext{
${ }^{4}$ See Hull (2000), pp. 271-272.

${ }^{5}$ Stucki (1992) reports that at-the-money options are the most actively traded options contracts on the Swiss exchange.

${ }^{6}$ See for example Patell and Wolfson (1981).
} 
the informational content of an earnings announcement, at least for the US market. ${ }^{7}$ For other markets, it may not be as accurate as shown by Benos and Rockinger (1998) for the French market. These authors have shown that another measure, the return on the announcement date, which was first proposed by Foster, Olsen and Shevlin (1984) is a more powerful means of discriminating between the informational content of good and bad news. The idea is that the nature of news has many dimensions, the difference between expected and realised earnings being just one of them. The return, on the other hand, captures the way the market has interpreted the announcement ex post. In order to take into account the general trend in the market, we compute abnormal return by subtracting the daily Swiss stock index-return (Swiss Market Index) to the raw daily stock return. The abnormal return will be our second measure to discriminate the informational content of the announcement. In our case, a drawback of using analysts' forecast errors is that it does not cover the totality of our sample. The I/B/E/S database provides information on slightly less than $58 \%$ of our events (103 announcements), which reduces considerably our information set. Another problem is that $\mathrm{I} / \mathrm{B} / \mathrm{E} / \mathrm{S}$ data are monthly and therefore assume that analysts revise their estimates once a month. It may well be that before an announcement, analysts revise their estimates more frequently and that the difference computed with $\mathrm{I} / \mathrm{B} / \mathrm{E} / \mathrm{S}$ data may not be the real surprise which happened on the event day. Other partition criteria have been used in the accounting and corporate finance literature. These are: the sign of the announced EPS, the sign of the difference between EPS and $\mathrm{EPS}_{\mathrm{t}-1}$, the difference between $\mathrm{EPS}_{\mathrm{t}}$ and $\left(\alpha+\beta \cdot \mathrm{EPS}_{\mathrm{mt}}\right)$, (where $\mathrm{EPS}_{\mathrm{mt}}$ represents the earnings of the whole market at time t, and $\alpha$ and $\beta$ are firm-specific parameters estimated on a previous period). As these measures are only based on realisations of EPS and do not consider the market's expectations about earnings, we do not use them to identify the informational content of earnings announcements. For both measures we use a $0 \%$ breakpoint to discriminate between good and bad news. According to the abnormal return criterion, the whole sample contains 92 good news announcements characterised by a positive abnormal stock return on date 0 and 86 cases of bad news characterised by a negative (or null) abnormal stock return on date 0 . According to the $\mathrm{I} / \mathrm{B} / \mathrm{E} / \mathrm{S}$ analysts' forecast error criterion, the subsample used contains 44 cases of good news characterised by a positive analyst's forecast error and 58 cases of bad news characterised by a negative (or null) analysts' forecast error.

\footnotetext{
${ }^{7}$ For an illustration of this type of study see Campbell, Lo and MacKinlay (1997), chapter 4.
} 


\section{Empirical results}

\subsection{Impact of earnings announcements on ISD}

We analyse first of all the evolution of the average ISD around earnings announcements on the whole sample of 178 announcements. Specifically, we compute the daily average ISD for an event window of 10 days before and after the information disclosure. Figure 4 shows the evolution of the average ISD around the event date. ${ }^{8}$

Figure 4: Evolution of ISD around earnings announcements for Swiss firms

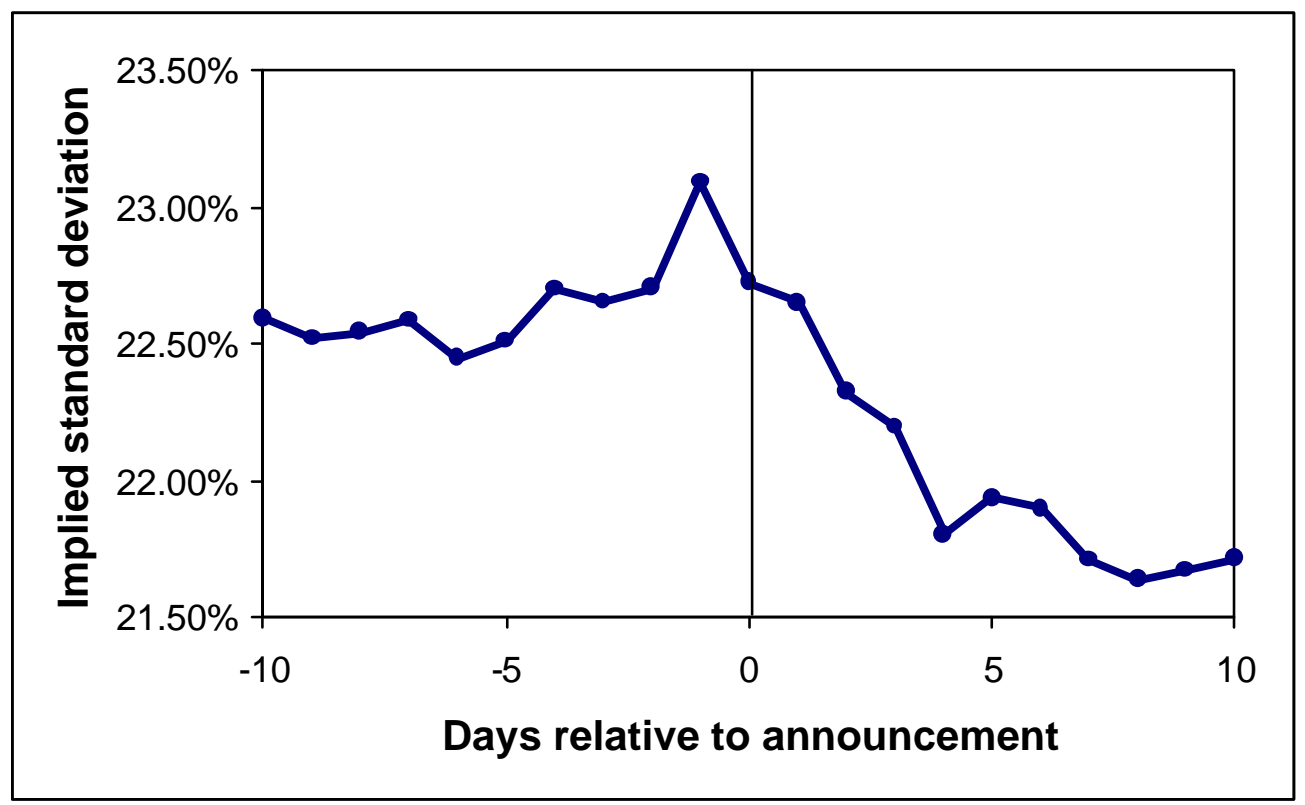

Note: The ISD is computed by applying the Roll-Geske-Whaley formula to at-the-money options with at least 20 days to maturity. Each point represents the average ISD over the 178 events on a particular day. Day 0 is the earnings announcement date.

The results display a pattern similar to that presented in figure 2. There is a slight increase in the average ISD before the information disclosure, indicating that the market expects some uncertainty on the event day. On the announcement date, the average ISD decreases and it

\footnotetext{
${ }^{8}$ Our results are presented in terms of the raw ISD. We also investigated the behaviour of market-adjusted ISD as proposed by Donders and Vorst (1996). All the results we obtained were qualitatively very similar to those
} 
continues to decrease during the next 4 days, indicating some persistence in the instantaneous volatility and also the presence of events containing bad news. This is in contrast with the results obtained by Donders and Vorst (1996), who find that the ISD decreases sharply on the announcement day and those of Donders, Kouwenberg and Vorst (2000), who report a 2-day decrease.

In order to investigate more formally the results displayed in figure 1, we compare the level of the ISD before and after the event in table 1. This table shows the average change in the ISD on a given date before and after the event. For instance, in the mean column we observe that on average, the ISD is $3.85 \%$ lower 10 days after the event than 10 days before. Formal tests of these changes are provided by the standard t-test on the mean and also by non-parametric tests on the median change. We also provide the percentage of cases (events) where there is a reduction in the ISD after the event.

Table 1: Comparison of pre- and post-event ISD

\begin{tabular}{|c|c|c|c|c|c|c|}
\hline $\begin{array}{c}\text { Days } \\
\mathrm{t}_{1}: \mathrm{t}_{2}\end{array}$ & $\begin{array}{c}\text { Mean }(\mu) \text { of } \\
\ln \left(\sigma_{\mathrm{t} 2} / \sigma_{\mathrm{t} 1}\right)\end{array}$ & $\begin{array}{c}\text { Standard- } \\
\text { deviation of } \\
\ln \left(\sigma_{\mathrm{t} 2} / \sigma_{\mathrm{t} 1}\right)\end{array}$ & $\begin{array}{c}\mathrm{t}-\mathrm{stat} \\
\left(\mathrm{H}_{0}: \mu=0\right)\end{array}$ & $\begin{array}{c}\text { Median }(\mathrm{M}) \\
\text { change }\end{array}$ & $\begin{array}{c}\text { Wilcoxon } \\
\left(\mathrm{H}_{0}: \mathrm{M}=0\right)\end{array}$ & $\begin{array}{c}\% \text { of events } \\
\text { where } \\
\ln \left(\sigma_{\mathrm{t} 2} / \sigma_{\mathrm{t} 1}\right)<0\end{array}$ \\
\hline$-1: 0$ & -0.0179 & 0.0976 & $-2.44^{*}$ & -0.0205 & $2.64^{*}$ & $56.18 \%$ \\
\hline$-10:+10$ & -0.0385 & 0.1623 & $-3.16^{*}$ & -0.0366 & $2.92^{*}$ & $57.87 \%$ \\
\hline$-9:+9$ & -0.0379 & 0.1524 & $-3.32^{*}$ & -0.0242 & $2.71^{*}$ & $55.06 \%$ \\
\hline$-8:+8$ & -0.0423 & 0.1623 & $-3.47^{*}$ & -0.0257 & $2.92^{*}$ & $60.11 \%$ \\
\hline$-7:+7$ & -0.0422 & 0.1520 & $-3.70^{*}$ & -0.0302 & $3.43^{*}$ & $61.24 \%$ \\
\hline$-6:+6$ & -0.0210 & 0.1582 & -1.77 & -0.0174 & $2.06^{*}$ & $57.87 \%$ \\
\hline$-5:+5$ & -0.0223 & 0.1673 & -1.78 & -0.0126 & 1.50 & $55.62 \%$ \\
\hline$-4:+4$ & -0.0387 & 0.1525 & $-3.38^{*}$ & -0.0145 & $2.71^{*}$ & $57.87 \%$ \\
\hline$-3:+3$ & -0.0187 & 0.1531 & -1.63 & -0.0186 & $2.11^{*}$ & $56.74 \%$ \\
\hline$-2:+2$ & -0.0155 & 0.1217 & -1.70 & -0.0174 & 1.88 & $58.43 \%$ \\
\hline$-1:+1$ & -0.0194 & 0.0990 & $-2.61^{*}$ & -0.0094 & $2.71^{*}$ & $54.49 \%$ \\
\hline
\end{tabular}

Note: This table compares the change in the ISD between dates $t_{1}$ and $t_{2}$. The second column gives the average change in the ISD, the second its standard deviation and the third a t-test that the average change is equal to zero. The next two columns give the median change and a non-parametric test that the median is equal to zero. The last column gives the percentage of events with negative changes. * indicates that a figure is significant at the $5 \%$ confidence level.

The results indirectly confirm implications I1 and I2, in the sense that the post-event ISD is shown to be on average significantly lower than the pre-event ISD. To be more precise, the 
ISD is significantly lower at the $5 \%$ level in 6 out of 10 cases with parametric tests and also in 8 cases with non-parametric tests. Moreover, the proportion of cases with lower ISD is always larger than $50 \%$. This table confirms the results of figure 4 for the average change in the ISD on the earnings announcement date. We observe that on average the ISD decreases by $1.79 \%$, a drop that is significant according to parametric and non-parametric tests. In order to document more accurately the evolution of the ISD over time, we run a regression using dummy explanatory variables. We regress the daily variation in the ISD on a constant, a dummy variable for the event date and dummy variables covering the post-event period.

$$
d I S D_{i t}=\alpha+\beta D_{\text {event }}+\sum_{n=1}^{10} \gamma_{n} D_{n}+\varepsilon_{i t} \quad \text { for } i=1, \ldots, 178 \text { and } t=-9, \ldots,+10
$$

$d I S D_{i t}=\ln \left(I S D_{i t} / I S D_{i t-1}\right)$ is the daily variation in the ISD for event $i$ on day $t$. It contains the change in the ISD for all the dates in our sample. $D_{\text {event }}$ is a dummy which equals 1 on the event date and zero for all other dates. $D_{n}$ is a dummy which equals 1 on the $n$-th day after the event date and zero otherwise. The results of this regression are given in table 2 .

\section{Table 2: Regression analysis of daily changes in ISD around earnings announcements}

\begin{tabular}{|c|c|c|c|}
\hline Variables & All news & Good news & Bad news \\
\hline constant & 0.0034 & 0.0001 & 0.0058 \\
\hline $\mathrm{D}_{\text {event }}$ & $-0.0213^{*}$ & $-0.0325^{*}$ & -0.0081 \\
\hline $\mathrm{D}_{+1}$ & -0.0089 & $-0.0239^{*}$ & 0.0080 \\
\hline $\mathrm{D}_{+2}$ & $-0.0289^{*}$ & $-0.0315^{*}$ & $-0.0253^{*}$ \\
\hline $\mathrm{D}_{+3}$ & -0.0092 & 0.0019 & -0.0205 \\
\hline $\mathrm{D}_{+4}$ & $-0.0314^{*}$ & -0.0225 & $-0.0403^{*}$ \\
\hline $\mathrm{D}_{+5}$ & 0.0015 & 0.0056 & -0.0017 \\
\hline $\mathrm{D}_{+6}$ & -0.0038 & 0.0010 & -0.0077 \\
\hline $\mathrm{D}_{+7}$ & -0.0138 & -0.0154 & -0.0109 \\
\hline $\mathrm{D}_{+8}$ & -0.0096 & -0.0030 & -0.0153 \\
\hline $\mathrm{D}_{+9}$ & 0.0021 & 0.0058 & -0.0006 \\
\hline $\mathrm{D}_{+10}$ & -0.0030 & -0.0006 & -0.0042 \\
\hline$N$ & 3560 & 1840 & 1720 \\
\hline
\end{tabular}

Note: Every column gives the estimates of equation (3). The good/bad news partition criterion is the sign of the stock abnormal return on the announcement date using a $0 \%$ breakpoint. $N$ is the number of observations in each sample. * indicates that a figure is significant at the $5 \%$ confidence level on the basis of t-statistics corrected for heteroscedasticity using the White method.

The estimated $\alpha$ coefficient in equation (3) measures the average variation of the ISD over the whole period with a correction for the event and post-event period. The estimated $\alpha$ provides 
a direct test of I1, i.e. does the ISD increase before the event date? The results of the estimation indicate that the ISD increases on average at a rate of $0.3 \%$ per day but this figure is not significant. Looking closer at figure 4 , we see that from day -10 until day -6 the ISD is flat and increases only from day -5 to day -1 . This means that I1 is only weakly confirmed.

The estimated $\beta$ coefficients measure the average deviation from the constant $\alpha$ on the event date; in other words, the sum of the $\beta$ and $\alpha$ coefficients measures the average variation of the ISD on the event date. Its Student statistic is given by $t=(\alpha+\beta) / \sigma(\alpha+\beta)$ where $\sigma^{2}(\alpha+\beta)=$ $\sigma^{2}(\alpha)+\sigma^{2}(\beta)+2 \operatorname{cov}(\alpha, \beta)$. Preliminary results shown in table 1 are confirmed: there is a significant drop in the ISD on the earnings announcement date. Analysing the results for the $\gamma$ coefficients in equation (3), we observe that they are negative during the post-event period and that the sum of the $\gamma$ coefficient with the constant is significantly different from zero on days 2 and 4. This confirms implication I2, that the ISD decreases after the event, when the whole sample is considered. Moreover, as we report a significant drop in the ISD during the 4 days following the news release, the persistence of instantaneous volatility shocks is confirmed.

\subsection{Distinguishing between good and bad news using abnormal stock returns}

We now investigate whether the ISD behaves differently according to the content of announcement as hypothesised in section 2. We first dissociate the events containing good news from those containing bad news by means of the abnormal return observed on stocks on the announcement date. We compute the average daily ISD for both groups for 20 days around the earnings announcement date. The results are presented in figure 5. 


\section{Figure 5: Evolution of ISD for good and bad news according to abnormal stock returns}

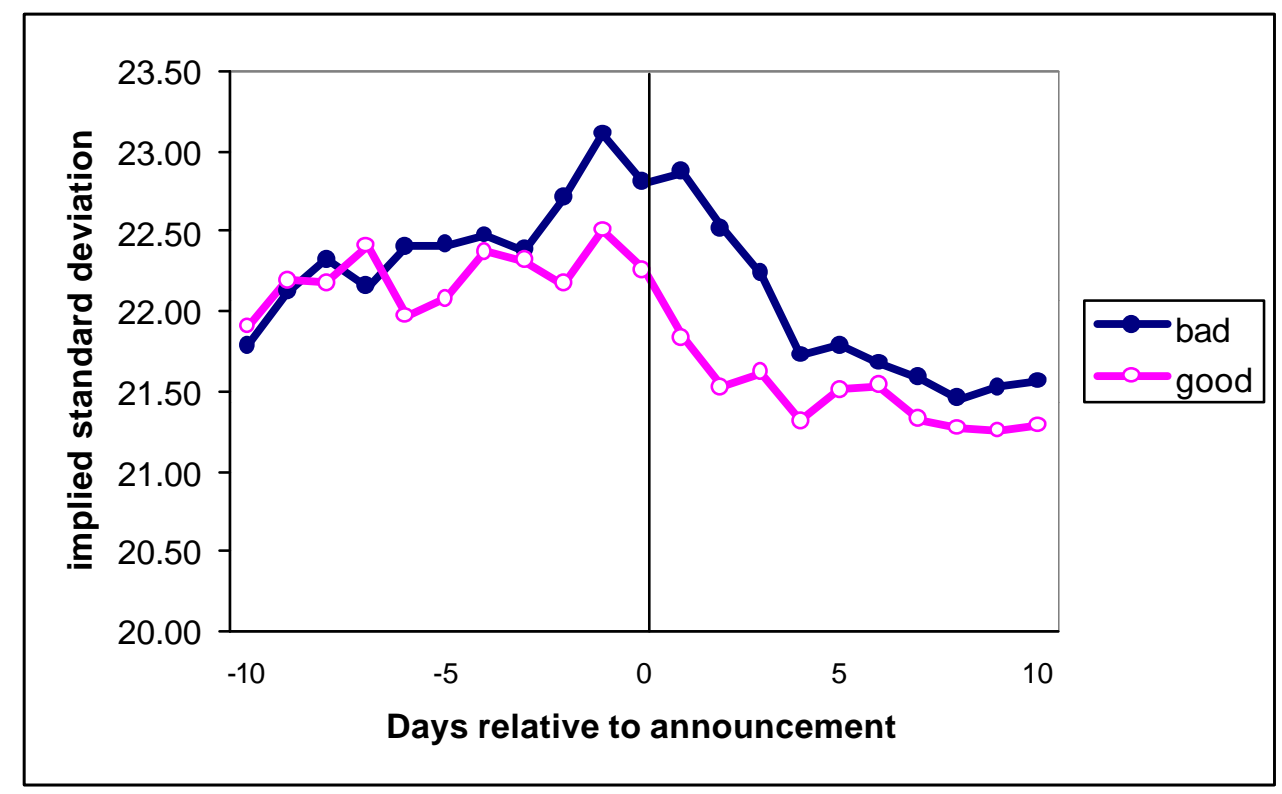

Note: The ISD is computed by applying the Roll-Geske-Whaley formula to at-the-money options with at least 20 days to maturity. Each point represents the average ISD over the 178 events on a particular day. Day 0 is the earnings announcement date. The good news sample contains events generating a positive abnormal stock return on day 0 and the bad news sample contains events generating a negative (or null) abnormal stock return on day 0 .

We see that the behaviour of the ISD is generally in accordance with the implications presented in section 2. In the case of good news, the ISD drops on day 0 and decreases slowly to its long-term level in 4 days. On the other hand, in the case of bad news, we observe that the ISD does not decrease from day 0 but remains particularly high for 2 days. During the post-announcement period, the ISD path following bad news always lies above the ISD path following good news. This result confirms implication 4 and is thus in accordance with the leverage argument.

Table 2 also reports the results from the regression 1 for good and bad news announcements. We first observe that for good and bad news the pre-event period is characterised by a very modest positive average (the constant in the regression) but it is not significant. As for the whole sample, this only weakly confirms I1. After good news, the decrease on the event date is significant (t-stat Devent $=-3.56$ ) and larger than for the whole sample, which confirms I3. After bad news, the coefficient is not different from 0 ( $\mathrm{t}$-stat Devent $=-0.22$ ). The post-event 
period also presents some differences. For the good news subsample, significant negative coefficients are also reported for the first two days following the announcement. For the bad news subsample, the decrease starts later as significant negative coefficients are reported for days 2,3 and 4 .

\subsection{Distinguishing between good and bad news using analysts' forecast errors}

A similar type of analysis is performed with events discriminated according to the analysts' forecast errors. The results can unfortunately not be compared with those of the previous subsection, as the sample is smaller and data is available from the I/B/E/S database for 103 earnings announcements. Events conveying good and bad news are determined on the basis of analysts' forecast errors using a $0 \%$ breakpoint.

Table 3: Regression analysis of daily changes in ISD around earnings announcements using subsamples

\begin{tabular}{|c|c|c|c|c|c|}
\hline Variables & All news & $\begin{array}{c}\text { Good news } \\
\text { I/B/E/S }\end{array}$ & $\begin{array}{c}\text { Bad news } \\
\text { I/B/E/S }\end{array}$ & $\begin{array}{c}\text { Good news } \\
\text { AR }\end{array}$ & $\begin{array}{c}\text { Bad news } \\
\text { AR }\end{array}$ \\
\hline constant & 0.0009 & 0.0003 & 0.0013 & -0.0005 & 0.0027 \\
\hline $\mathrm{D}_{\text {event }}$ & $-0.0327^{*}$ & $-0.0268^{*}$ & $-0.0372^{*}$ & $-0.0484^{*}$ & -0.0106 \\
\hline $\mathrm{D}_{+1}$ & -0.0188 & -0.0206 & -0.0180 & $-0.0384^{*}$ & 0.0059 \\
\hline $\mathrm{D}_{+2}$ & $-0.0222^{*}$ & -0.0232 & -0.0219 & -0.0172 & $-0.0303^{*}$ \\
\hline $\mathrm{D}_{+3}$ & $-0.0234^{*}$ & -0.0237 & -0.0213 & -0.0099 & $-0.0388^{*}$ \\
\hline $\mathrm{D}_{+4}$ & $-0.0329^{*}$ & $-0.0310^{*}$ & $-0.0332^{*}$ & -0.0225 & $-0.0459^{*}$ \\
\hline $\mathrm{D}_{+5}$ & 0.0018 & 0.0096 & -0.0042 & -0.0034 & 0.0088 \\
\hline $\mathrm{D}_{+6}$ & 0.0044 & -0.0014 & 0.0089 & 0.0050 & 0.0037 \\
\hline $\mathrm{D}_{+7}$ & -0.0154 & -0.0015 & -0.0262 & -0.0182 & -0.0116 \\
\hline $\mathrm{D}_{+8}$ & -0.0084 & 0.0043 & -0.0182 & -0.0017 & -0.0174 \\
\hline $\mathrm{D}_{+9}$ & 0.0040 & -0.0011 & 0.0080 & -0.0005 & 0.0101 \\
\hline $\mathrm{D}_{+10}$ & 0.0035 & -0.0088 & 0.0130 & 0.0088 & -0.0038 \\
\hline$N$ & 2060 & 900 & 1160 & 1180 & 880 \\
\hline
\end{tabular}

Note: Every column gives the estimates of equation (3). The good/bad news partition criteria are the sign of the analysts' forecast error (I/B/E/S) and the sign of the stock abnormal return (AR) on the announcement date using a $0 \%$ breakpoint. $N$ is the number of observations in each sample. * indicates that a figure is significant at the $5 \%$ confidence level on the basis of t-statistics corrected for heteroscedasticity using the White method. 
We give the results of the regression analysis for both subsamples in table 3. According to the above regression using the forecast error as a partition criterion, we report for the good news subsample a drop in the ISD on the announcement day and then a continuous decrease from day 0 . However, reported figures are not significant at the $5 \%$ confidence level. For the bad news subsample, we also report a substantial drop on the announcement day and an uninterrupted fall of the ISD until day 5. The fact that both subsamples present a similar behaviour when the nature of news is determined by the analysts' forecast errors indicates that the ISD does not react the same way to bad surprises in earnings as it does to negative (abnormal) returns on the event dates. This is probably due to the fact that an earnings surprise is just one dimension of the informational content of an earnings announcement. It may well be that a bad surprise is accompanied by encouraging news concerning the company's prospects, which could compensate for the bad news generated by results below those that were expected by the analysts. On the other hand, the return captures the way the market has reacted to the earnings announcement in all its dimensions. It could very well be that a negative return is associated with a positive earnings surprise. These differences could also be due to the fact that the earnings forecasts we use are revised every month and that the analysts may revise their forecasts more frequently before an earnings announcement. These more frequent revisions before an announcement date are therefore not reflected in our data and could be responsible for the lack of correspondence between the two measures and the difference in results for the evolution of the ISD.

For the sake of completeness and in order to check if the reported results are not due to the fact that the set of data used with the analysts' forecast error is smaller, we run regression 3 with the whole 103 event data set (All news) and using the abnormal return partition criterion (Good news AR, Bad news AR). The estimated coefficients are also reported in table 3. It is interesting to note that the results based on abnormal returns hold for this smaller data set. This additional comparison confirms that the two partition criteria give different results and seem not to capture the same information. 


\section{Conclusion}

This paper investigates the evolution of market uncertainty around earnings announcement dates, more specifically the behaviour of the volatility implied in option prices around these events. This volatility is widely regarded as the option market's forecast of future volatility over the remaining life of the option. Based on this definition, previous literature has proposed a model of evolution of the ISD assuming that the instantaneous volatility increases on the day of the information disclosure and remains at a constant level on the other days. This paper proposes testable implications based on empirical observations of the dynamics of the instantaneous volatility. These implications are then empirically investigated on a comprehensive sample of firms having quoted options on the Swiss market over the period 1989-1998. The results indicate that it takes several days for the ISD to return to its long-term level after an earnings announcement, confirming the persistence of volatility shocks. The leverage effect is investigated by dividing our sample into a good news subsample and a bad news subsample using two different partition criteria, namely the abnormal return on the event date and the analysts' forecast errors computed with the I/B/E/S database. The results show that the post-announcement ISD path depends on the content of the earnings announcement. However, when the content is appraised using earnings surprises, we do not report any difference in the behaviour of the ISD between the two subsamples. This may be due to the fact that the earnings surprise is not the sole determinant of the informational content of the earnings announcement and to the fact that analysts revise their forecasts more frequently before a company discloses its results. The conclusion of these investigations is that the behaviour of the ISD reflects the presence of the leverage effect when bad news is defined as information causing large drops in stock prices on the earnings announcement date. One of the contributions of the paper is to show that the leverage effect which is usually documented for stock returns is also present in the volatilities recorded on option markets. 


\section{References}

Adjaoute K., M. Bruand and R. Gibson-Asner, 1998. On the predictability of the stock market: Does history matter? European Financial Management 4, 287-292.

Bailey W., 1988. Money supply announcements and the ex-ante volatility of asset prices, Journal of Money, Credit and Banking 20, 611-620.

Ball R. and P. Brown, 1968. An empirical evaluation of accounting income numbers, Journal of Accounting Research 6, 159-178.

Benos A. and M. Rockinger, 1998. Market response to earnings announcements and interim reports: An analysis of SBF120 companies, Working Paper, HEC Paris.

Black F., 1976. Studies of stock price volatility changes, Proceedings of the American Statistical Association, 177-181.

Black F. and M. Scholes, 1973. The pricing of options and corporate liabilities, Journal of Political Economy 81, 637-654.

Bollerslev T., R. Chou and K. Kroner, 1992. ARCH modeling in finance: A review of the theory and empirical evidence, Journal of Econometrics 52, 5-59.

Campbell J., A. Lo and C. MacKinlay, 1997. The Econometrics of Financial Markets (Princeton University Press, Princeton).

Christensen B. J. and N. R. Prabhala, 1998. The relation between implied and realized volatility, Journal of Financial Economics 50, 125-150.

Donders M. and T. Vorst, 1996. The impact of firm specific news on implied volatilities, Journal of Banking and Finance 20, 1447-1461.

Donders M., R. Kouwenberg and T. Vorst, 2000. Options and earnings announcements: An empirical study of volatility, trading volume, open interest and liquidity, forthcoming in European Financial Management 6 (2).

Duan J.-C., 1995. The GARCH option pricing model, Mathematical Finance 5, 13-32

Ederington L. and J. Lee, 1996. The creation and resolution of market uncertainty: The impact of information releases on implied volatilities, Journal of Financial and Quantitative Analysis 31 (4), 513-540.

Foster G., C. Olsen and T. Shevlin, 1984. Earnings releases, anomalies and the behavior of security returns, Accounting Review 59, 574-603.

French D. and D. Dubofsky, 1986. Stock splits and implied stock price volatility. Journal of Portfolio Management 12 (4), 55-59. 
Heynen R., A. Kemna and T. Vorst, 1994. Analysis of the term structure of implied volatilities, Journal of Financial and Quantitative Analysis 29, 31-56.

Hull J., 2000. Options, futures, and other derivatives (Prentice Hall International, New York).

Hull J. and A. White, 1987. The pricing of options on assets with stochastic volatilities, Journal of Finance 42, 281-300.

Latané H. and R. Rendleman, 1976. Standard deviations of stock price ratios implied in options prices, Journal of Finance 31, 369-381.

Levy H. and J. Yoder, 1993. The behavior of option implied standard deviations around merger and acquisition announcements, Financial Review 28, 261-272.

Merton R., 1973. Theory of rational option pricing, Bell Journal of Economics and Management Science 4, 141-183.

Patell J. and M. Wolfson, 1979. Anticipated information release reflected in call option prices, Journal of Accounting and Economics 1, 107-140.

Patell J. and M. Wolfson, 1981. The ex ante and ex post price effects of quarterly earnings announcements reflected in option and stock prices, Journal of Accounting Research $19(2), 434-458$.

Sahlström P., 2000. Use of implied volatility in measuring abnormal stock returns: evidence of the earnings announcements in Finland, Working Paper, University of Vaasa, Finland.

Sheikh A., 1989. Stock splits, volatility increase, and implied volatilities. Journal of Finance 44 (5), 1361-1372.

Stucki T., 1992. Eigenschaften der impliziten volatilitäten der SOFFEX-optionen, Finanzmarkt und Portfolio Management 6, 396-413. 